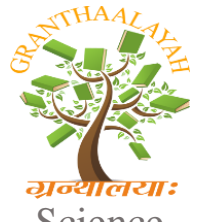

\author{
INTERNATIONAL JOURNAL OF RESEARCH - \\ GRANTHAALAYAH \\ A knowledge Repository
}

\title{
PREVALENCE OF UNSOLVED DRINKING PROBLEMS FOR DUI DRIVERS REFERRED FOR MEDICAL EVALUATION IN SWITZERLAND
}

\author{
M. De Cesare*1, V.Jomini², R.Selz ${ }^{2}$, P. Mangin ${ }^{2}$, P.Vaucher ${ }^{2}$, B. Favrat ${ }^{2}$, M. Augsburger ${ }^{2}$ \\ ${ }^{* 1}$ Unit of Psychology and Traffic Medicine (UMPT) of Ticino, Via Trevano 4, 6901 \\ Lugano, SWITZERLAND \\ ${ }^{2}$ University Centre of Legal Medicine, Lausanne-Geneva, Rue du Bugnon 21, 1011 Lausanne, \\ SWITZERLAND
}

\begin{abstract}
Estimate the proportion of heavy DUI offenders who do not initiate a treatment for their drinking problem before referring to an official medical expertise to recover their driver's license. Evaluate the proportion of offenders with drinking problems who became abstinent during 6 months within two years after their offense and their characteristics. Between January 2010 and December 2012, data were collected from 1316 consecutive drivers who were referred to an expertise in a legal medicine Swiss institute to recover their driver's license after driving under the influence of alcohol. 153 offenders were included in the analysis after excluding patients under the influence of other recreational drugs and patients unfit to drive for other medical reasons. Heavy DUI were defined as first time drunk driving offenders with blood alcohol concentration $(B A C) \geq 2.50 \mathrm{~g} / \mathrm{kg}$, or second-time drunk driving offenders within five years with $B A C \geq 1.60 \mathrm{~g} / \mathrm{kg}$ in five years, or third-time drunk driving offenders within ten years with $B A C \geq 0.80 \mathrm{~g} / \mathrm{kg}$. 28 subjects of $153(18 \%)$ were considered fit to drive. The rest of the drivers (125, 82\%) were considered unfit to drive (drinking problem 77, dissociation alone 48). The majority of offenders $(46,4 \%)$ had driving under the influence of alcohol 2 times in the last five years with $B A C \geq 1.60 \mathrm{~g} / \mathrm{Kg}, 65$ (42.5\%) had $B A C \geq 2.5$ and the rest had 3 or more drunk driving offenses. The criteria used for medical and/or psychological assessment are appropriate.
\end{abstract}

Keywords:

Alcohol-related problems, BAC; DUI, Drunk driving offenders; Expertise, Traffic medicine.

Cite This Article: M. De Cesare, V.Jomini, R.Selz, P. Mangin, P.Vaucher, B. Favrat, and M. Augsburger, "PREVALENCE OF UNSOLVED DRINKING PROBLEMS FOR DUI DRIVERS REFERRED FOR MEDICAL EVALUATION IN SWITZERLAND” International Journal of Research - Granthaalayah, Vol. 3, No. 9(2015): 14-22.

\section{INTRODUCTION}

The blood/alcohol limit in Switzerland is 50 milligrams of alcohol per 100 millilitres of blood (0.5 grams/litre). According to Swiss Council for Accident Prevention, in 2012, only 7 drivers out of 
10 are capable of naming the currently applicable blood-alcohol limit (BPA, Rapport SINUS 2013). Therefore, it will not be surprising that driving under the influence of alcohol is common in our country. The Federal Statistics Office (FSO 2013) estimated than $8.8 \%$ of drivers tested for their alcohol level in 2012 had a blood alcohol concentration equalling or exceeding $0.5 \%$. During the same year, there were 14'763 convictions for drunk drivers with BAC qualified (>0.8\%o). There is also a slight increase in the number of punishment between 1990 and 2012; in 2012, 17'105 licences have been withdrawn for driving under the influence of alcohol.

Switzerland has set up a rigorous program to identify drunk drivers and then to refer them. Swiss Traffic Law specifies which drivers are to be referred by the Cantonal Driver and Vehicle Licensing Agency to a specialized institute for expert review (medical and/or psychological assessment to determine the presence (or not) of an alcohol problem). The authorities require an expert review whenever impaired fitness to drive is suspected; for example, when there is evidence of addiction (from a police or medical report). A review may also be requested even if no traffic offense has been committed. In most cases, however, one or more traffic offenses indicate an impaired fitness to drive. The expert review determines the nature and severity of the impairment and a written report is submitted to the authorities (Muschovich \& Haag-Dawoud 2012).

In the Canton of Vaud (French speaking Switzerland, 800,000 inhabitants), the UMPT (Unit of Psychology and Traffic Medicine) in Lausanne has monitored fitness to drive for many years. When inability to drive is presumed for medical, psychological or psychiatric reasons, the unit is asked to prepare an expert evaluation for the Department of Motor Vehicles and Navigation (SAN). After this assessment, the expert determines whether the driver is considered unfit to drive, fit to drive, or fit to drive only under conditions. In the last case, appropriate restrictions are recommended; for example, abstention from alcohol and/or drugs. Conditions related to treatment may also be imposed. In case of unfitness, the driver is required to undergo a specialized followup in order to recover his/her license to drive.

The aim of this study is to estimate the proportion of heavy DUI offenders who do not initiate a treatment for their drinking problem before referring to an official medical expertise to recover their driver's license. Evaluate the proportion of offenders with drinking problems who became abstinent during 6 months within two years after their offense and their characteristics according to the current medical-psychological assessment (Roche et al. 1991; Bradley et al. 1995; Rollnick, Butter \& Hodgson 1997; Andréasson, Hjalmarsson \& Rehnmen 2000; Wilson et al. 2011).

\section{METHODS}

\section{DESIGN}

This cohort study followed severe DUI for two years to compare abstinence success and recovery of driver's license for different types of DUI offenses following a standardized procedure of expertise.

\section{POPULATION}

Data was collected for a consecutive sample of severe DUI without any other possible cause of unfitness to drive (e.g. know consumption of other recreational drugs, other medical condition) 
attending two experts in our Unit between January 2010 and December 2012. The flowchart (Fig.1) shows the process used for selecting the data to collect.

\section{SEVERE DUI STATUS}

Prior to the expertise, the Cantonal Driver and Vehicle Licensing Agency provided for each participant the following information: date of the offense, date of judgment, BAC, prior offenses related to alcohol and related BAC, and police report. Severe DUI were classified in three groups depending of their type of offense: 1) first time drunk driving offenders with blood alcohol concentration $(\mathrm{BAC}) \geq 2.50 \mathrm{~g} / \mathrm{kg}$ (BAC $\geq 2.5)$, 2) second-time drunk driving offenders within five years with $\mathrm{BAC} \geq 1.60 \mathrm{~g} / \mathrm{kg}$ in five years $(2 \times B A C \geq 1.6)$, and 3$)$ third-time drunk driving offenders within ten years with $\mathrm{BAC} \geq 0.80 \mathrm{~g} / \mathrm{kg}(3 \times \mathrm{BAC} \geq 0.8)$.

\section{DEFINING ABSTINENCE}

Cases were defined as DUI with drinking problems who attended a medico-social curing program and were abstinent of alcohol consumption during the six prior months within the two years following their first expertise. Abstinence was assessed during a second expertise and documented by either a monthly blood sample revealing normal CDT, GGT, ASAT and ALAT concentrations, or by analyzing hair sample from the six previous months for ethyl glucuronide (EtG) (Muschovich \& Haag-Dawoud 2012).

\section{PROCEDURE}

Severe DUI were informed by letter that an expertise was requested to attest the absence of drinking problems to recover their driver's license. On their initiative, they then contacted our unit for an expertise. The convocation letter provided details on the procedure and requested them to moderate their consumption of alcohol during the three weeks that preceded the expertise.

The expertise itself was standardized. Particular care was taken in assuring that both experts introduced the aim and reason for the expertise in a similar manner. Prior to questioning them on their drinking behavior, participants were informed that a blood sample would be collected revealing their alcohol consumption during the three previous weeks. They were also told that the expertise aimed to detect an eventual drinking problem and help them find medical solutions to their problem if it was to be the case. They were informed that it was in their interest to be as sincere and honest as possible in the answers they were to provide as there are to be confronted to possible contradictions with other exams. Each case was supervised by the same manager.

\section{LABORATORY EXAMS}

During the expertise, consumption of alcohol of the subjects is clinically and biologically controlled through a blood sample to revealing CDT, GGT, ASAT and ALAT concentrations.

\section{STATISTICAL METHODS}

The statistical analysis was performed using STATA 12.0. P-values are provided using Fischer's exact test. Significance level was set at $\mathrm{P} \leq 0.05$. 


\section{RESULTS}

\section{CHARACTERISTICS OF THE DRIVERS}

The main characteristics of the drivers are presented in Table 1. As observed in other studies (Mura et al. 2003), males (136 of 153, 88.9\%) heavily predominated over females (17 of 153, 11.1\%). The age group of the drivers was: $\leq 25$ years $=5(3.3 \%), 25-44$ years $=77(50.3 \%), 45-64$ years $=$ $65(42.5 \%), \geq 65$ years $=6(3.9 \%)$.

\section{TYPES OF DRINKING PROBLEMS}

The conclusion of the expert evaluation was classified in fit or unfits to drive and the specific reason for unfitness is given. The type of drinking problems at time of expertise are presented in Table I. 28 subjects of 153 (18\%) were considered fit to drive. The rest of the drivers $(125,82 \%)$ were considered unfit to drive (drinking problem 77, dissociation alone 48). The results of BAC from all drivers investigated are shown in table I. The majority $(46,4 \%)$ had driving under the influence of alcohol 2 times in the last five years with $\mathrm{BAC} \geq 1.60 \mathrm{~g} / \mathrm{Kg}, 65(42.5 \%) \mathrm{had} \mathrm{BAC} \geq$ 2.5 and the rest had 3 or more drunk driving offenses.

\section{PREVALENCE OF OFFENDERS HAVING ADDRESSED DRINKING PROBLEM BEFORE MEDICAL EXPERTISE}

None of the 153 offenders had undergone any form of medical investigation for their drinking problem prior to their medical expertise. When only considering those with alcohol related problems $(\mathrm{N}=125)$, the observed prevalence of those having had addressed their problem with alcohol was of $0 \%$ (CI95\% 0 to $2.9 \%$ ).

\section{PREVALENCE OF ABSTINENCE FOLLOWING MEDICAL EXPERTISE}

Details of offenders who were abstinent within the two years following their offense is provided in Table 2. The overall period prevalence of success over two years after the offense is of $49.6 \%$ (C195\% 40.5 to 58.7). This prevalence appeared to be independent of the type of problem, drinking problem or dissociation alone, or the type of offense.

\section{DISCUSSION}

\section{OVERVIEW OF OUR RESULTS}

Our cohort study reveals that most people failed to resolve their problem before coming to expertise in our Institute. The overall period prevalence of success over two years after the offense is of 49.6\% (CI95\% 40.5 to 58.7). This prevalence appeared to be independent of the type of problem, drinking problem or dissociation alone, or the type of offense. According to our data, 2544 years male subjects who are admitted to our center after à DUI are the primary target for any therapeutic intervention. The current measures are particularly suitable for drivers aged between 25 and 65 years. In agreement with O'Donnell and all. (2014), most of the results concerns the middle-aged men.

\section{CONTRAST WITH OTHER FINDINGS}

Del Rio and colleagues (2001) note that there are no valid tests or standardized criteria for identifying competency of drivers affected by alcohol dependency: 7 out of 10 drivers (70\%) in 
Spain who were diagnosed with alcohol-related problems were deemed fit to drive by the licensing authority’s Medical Driving Test Centers.

According to the research results of the report of 2009 of the Monash University Accident Research Centre (Charlton et al. 2010), the problem is how to identify the at-risk driver with a chronic alcohol problem. More informative assessments may also be important for targeting interventions that are specific to the needs of drink-driving offenders. Numerous studies (Reid et al. 1986, Buchsbaum 1994, Piccinelli et al. 1997, Conigliaro et all. 1998, Jeanrenaud et al. 2003, Kuending 2010), have demonstrated that problem drinkers (hazardous drinking, alcohol abuse and alcohol dependence) can benefit from medical intervention, but lack of recognition of alcohol related problems by primary health care workers has been frequently reported and a long-term total alcohol abstinence should be recommended for the latter group due to the poor medical prognosis (Muschovich \& Haag-Dawoud 2012). A study from Michigan suggests that more than 50\% of first offenders reoffend within 10 years (Voas \& Fisher, 2001). In Florida, however, where this study was conducted, the first-offender recidivism rate is as low as $17 \%$ over 10 years (personal communication from Milton Grosz, Florida Dept. of Highway Safety, 2006). National estimates show that, on average, one-third of the 1 million first-time DUI offenders arrested each year will reoffend (Voas \& Fisher, 2001). An alternative strategy for reducing alcohol-impaired driving lies in the control of driving. Research shows that attempts to limit drinking and driving are undermined by several influences that prevail at drinking events (McKnight et al, 1995). These findings strongly suggest that the best way to prevent driving after drinking is not to have access to an automobile, a condition ensured only by not driving to locations where alcohol will be available (Rider e al. 2007).

\section{LIMITATIONS OF THIS STUDY}

The only alcohol problem is rare and involved only 153 of $1316(11.6 \%)$ drivers who were referred to an expertise in our Institute to recover their driver's license (Fig.1). Also, the drink-driving offenders are reticent to report their alcohol problem to authorities and to their medical practitioners. In addition to this, the medical practitioners don't intervene in decisions about licensing.

\section{PRACTICAL APPLICATIONS}

We should perhaps think about putting into practice of precise measurements for $<25$ years and $>65$ years. These findings provide additional arguments for improve alcohol assessment and treatment in this population. Lenaerts et all. note in their systematic review (Lenaerts et all 2014), that there is weak evidence continuing care have a beneficial effect knew alcohol consumption, but it also highlights the lack of evidence for possible best practices. O'Donnell et all, (2014) reviewed the efficiency of brief interventions in primary care medicine to reduce alcohol consumption to risk and problems related to the consumption of alcool. Duration, frequency and content optimal brief intervention remain unclear. There are still unanswered questions regarding the components required for an intervention to be effective.

\section{CONCLUSION}

We hope that our study will contribute to developing the public understanding of the alcohol and driving problem in Switzerland, and could encourage policymakers and politicians to increase 
enforcement strategies and improve public awareness of different types of DUI offenses and the relevance of our procedure of expertise.

\section{REFERENCES}

[1] Alvarez FJ, Del Rio MC. Alcohol and driving. Lancet 1996;347(9007):985-986.

[2] Alvarez FJ, Del Rio MC. Screening for problem drinkers in a general population survey in Spain by use of the CAGE scale. Journal of studies on alcohol 1994;55(4):471-474.

[3] Andreasson S, Hjalmarsson K, Rehnman C. Implementation and dissemination of methods for prevention of alcohol problems in primary health care: a feasibility study. Alcohol and alcoholism (Oxford, Oxfordshire) 2000;35(5):525-530.

[4] Augsburger M, Rivier L. Drugs and alcohol among suspected impaired drivers in Canton de Vaud (Switzerland). Forensic Sci Int 1997;85(2):95-104.

[5] Berghaus G, Ramaekers JG, Drummer OH. Demands on scientific studies in different fields of forensic medicine and forensic sciences: Traffic medicine-Impaired driver: Alcohol, drugs, diseases. Forensic Science International 2007;165(2-3):233-237.

[6] Berghaus G. Meta-analyses in research in forensic medicine: Alcohol, drugs, diseases and traffic safety. Forensic Science International 2007;165(2-3):108-110.

[7] BPA - Bureau de prévention des accidents. Rapport SINUS 2013. Niveau de sécurité et accidents dans la circulation routière en 2012. Berne: bpa; 2013. ISSN 1664-5766 (version imprimée) ISSN 1664-5782 (PDF)

[8] Bradley KA, Curry SJ, Koepsell TD, Larson EB. Primary and secondary prevention of alcohol problems: U.S. internist attitudes and practices. Journal of general internal medicine 1995;10(2):67-72.

[9] Buchsbaum, D. Effectiveness of treatment in general medicine patients with drinking problems. Alcohol Health \& Research World 1994;18:140-145.

[10] Charlton J.L., Koppel S., Odell M., Devlin A., Langford J., O'Hare M., Kopinathan C., $\begin{array}{lllll}\text { Andrea D., } & \text { Smith } & \text { Khodr } & \text { B., }\end{array}$ Edquist J., Muir C., Monash University Accident Research Centre : "Influence of chronic illness on crash involvement of motor vehicle drivers: 2 nd edition" available at hhttp://w ww.monash.edu.au/miri/research/reports/muarc300.pdf

[11] Conigliaro J, Lofgren RP, Hanusa BH. Screening for problem drinking: impact on physician behavior and patient drinking habits. Journal of general internal medicine 1998;13(4):251-256.

[12] Del Rio, M. C., et al. (2001). "Alcohol-related problems and fitness to drive." Alcohol Alcohol 36(3): 256-261.

[13] Federal Office (FSO) Available at: http://www.bfs.admin.ch/bfs/portal/en/tools/search.html Accessed April 12, 2014.

[14] Guidelines of Swiss Society of Legal Medicine (Richtlinien der Schweizerischen Gesellschaft für Rechtsmedizin SGRM). Arbeitsgruppe haaranalytik. Die forensischtoxikologische Available at: http://www.sgrm.ch/uploads/media/rules_haaranalytik_03.pdf. Accessed april 12, 2014

[15] Jeanrenaud C, Pellegrini S: Evaluating psychosocial and behavioural effects of alchohol dependence: a contingent valuation study. Paper to be presented at the iHEA 4th World Conference, San Francisco, June 2003. 
[16] Kaner EF, Heather N, McAvoy BR, Lock CA, Gilvarry E. Intervention for excessive alcohol consumption in primary health care: attitudes and practices of English general practitioners. Alcohol and alcoholism (Oxford, Oxfordshire) 1999; 34(4):559-566.

[17] Kuendig H. Alcohol dependence figures in the swiss general population: a sisyphean challenge for epidemiologists. European addiction research 2010; 16(4):185-192.

[18] Lenaerts E, Matheï C, Matthys $F$, et al. Continuing care for patients with alcohol use disorders: Asystematic review. Drug Alcohol Dependence. 2014; 135:9-21.

[19] McKnight, A.J., Langston, E.A., Lange, J.E., McKnight, A.S. Development of standardized field sobriety tests for lower BAC limits. (Report prepared under NHTSA Contract no. DTNH22-92-C-00700). Washington, DC: US Department of Transportation, National Highway Traffic Safety Administration. 1995.

[20] Moyer A, Finney JW, Swearingen CE, Vergun P. Brief interventions for alcohol problems: a meta-analytic review of controlled investigations in treatment-seeking and nontreatment-seeking populations. Addiction 2002;97(3):279-292.

[21] Mura P, Kintz P, Ludes B, Gaulier JM, Marquet P, Martin-Dupont S, Vincent F, Kaddour A, Goulle JP, Nouveau J, Moulsma M, Tilhet-Coartet S, Pourrat O. Comparison of the prevalence of alcohol, cannabis and other drugs between 900 injured drivers and 900 control subjects: results of a French collaborative study. Forensic Sci Int 2003;133(12):79-85.

[22] Muskovich M, Haag-Dawoud M. Alcohol consumption among drivers subject to the Swiss license restriction of zero tolerance when driving. Traffic Inj Prev 2012;13(6):537-543.

[23] O'Donnell A., Anderson P, Newbury-Birch D, et al. The impact of brief alcohol interventions in primary healthcare: a systematic review of reviews. Alcohol Alcohol. 2014;49(I):66-78.

[24] Piccinelli, M., et al. Efficacy of the alcohol use disorders identification test as a screening tool for hazardous alcohol intake and related disorders in primary care: a validity study. Bmj 1997; 314(7078): 420-424.

[25] Reid, A., Webb, G.R., Hennrikus, D., Fahey, P.P. Detection of patients with high alcohol intake by general practitioners" Br. Med. J. 1996; 293: 735-737.

[26] Roche AM, Guray C, Saunders JB. General practitioners' experiences of patients with drug and alcohol problems. British journal of addiction 1991;86(3):263-275.

[27] Wilson GB, Lock CA, Heather N, Cassidy P, Christie MM, Kaner EF. Intervention against excessive alcohol consumption in primary health care: a survey of GPs' attitudes and practices in England 10 years on. Alcohol and alcoholism (Oxford, Oxfordshire) 2011;46(5):570-577.

[28] Rider, R., et al. Preventing alcohol-related convictions: the effect of a novel curriculum for first-time offenders on DUI recidivism. Traffic Inj Prev 2007; 8(2): 147-152.

[29] Voas, R. B. and Fisher A.Court procedures for handling intoxicated drivers. Alcohol Res Health 2007; 25(1): 32-42. 


\section{TABLES}

Table 1: Description of DUI severe offenders at time of expertise to attest absence of drinking problems

\begin{tabular}{|c|c|c|c|c|c|}
\hline & & \multicolumn{2}{|c|}{ Conclusion after expertise } & \multirow[b]{2}{*}{ P-value } & \multirow{2}{*}{$\begin{array}{c}\text { All severe } \\
\text { DUI } \\
\mathrm{N}=153\end{array}$} \\
\hline & $\begin{array}{l}\text { Fit to drive } \\
\qquad N=28\end{array}$ & $\begin{array}{c}\text { Drinking } \\
\text { problem } \\
\mathrm{N}=77 \\
\end{array}$ & $\begin{array}{c}\text { Dissociation alone } \\
\mathrm{N}=48\end{array}$ & & \\
\hline Gender; males & $25(89.3 \%)$ & $65(84.4 \%)$ & $46(95.8 \%)$ & $\mathrm{P}=0.128$ & $136(88.9 \%)$ \\
\hline Age & & & & $\mathrm{P}=0.244$ & \\
\hline$<25 \mathrm{yrs}$ & $3(10.7 \%)$ & $1(1.3 \%)$ & $1(2.1 \%)$ & & $5(3.3 \%)$ \\
\hline $25-44$ yrs & $15(53.6 \%)$ & $36(46.7 \%)$ & $26(54.2 \%)$ & & $77(50.3 \%)$ \\
\hline $45-64$ yrs & $10(35.7 \%)$ & $35(45.5 \%)$ & $20(41.7 \%)$ & & $65(42.5 \%)$ \\
\hline$\geq 65 \mathrm{yrs}$ & $0(0 \%)$ & $5(6.5 \%)$ & $1(2.1 \%)$ & & $6(3.9 \%)$ \\
\hline $\begin{array}{l}\text { Time between offense } \\
\text { and expertise }\end{array}$ & & & & $\mathrm{P}=0.594$ & \\
\hline$\leq 3$ months & $2(7.1 \%)$ & $2(2.6 \%)$ & $1(2.1 \%)$ & & $5(3.3 \%)$ \\
\hline 3-6 months & $12(42.9 \%)$ & $43(55.8 \%)$ & $23(47.9 \%)$ & & $78(51.0 \%)$ \\
\hline $6-12$ months & $8(28.6 \%)$ & $18(23.4 \%)$ & $17(35.4 \%)$ & & $43(38.1 \%)$ \\
\hline$>1$ year & $6(21.4 \%)$ & $14(18.2 \%)$ & $7(14.6 \%)$ & & $27(17.6 \%)$ \\
\hline $\begin{array}{l}\text { Reported history of } \\
\text { drinking problems }\end{array}$ & $2(7.1 \%)$ & $25(32.5 \%)$ & $15(31.2 \%)$ & $\mathrm{P}=0.020$ & $42(27.4 \%)$ \\
\hline Type of offense* & & & & & \\
\hline $\mathrm{BAC}>2.5 \mathrm{~g} / \mathrm{kg}$ & $14(50.0 \%)$ & $44(57.1 \%)$ & $7(14.6 \%)$ & $\mathrm{P}<0.001$ & $65(42.5 \%)$ \\
\hline BAC $2 x>1.6 \mathrm{~g} / \mathrm{kg}$ & $14(50.0 \%)$ & $33(42.9 \%)$ & $24(50.0 \%)$ & $P=0.680$ & $71(46.4 \%)$ \\
\hline BAC $3 x>0.8 \mathrm{~g} / \mathrm{kg}$ & $2(7.1 \%)$ & $9(11.7 \%)$ & $20(41.7 \%)$ & $\mathrm{P}<0.001$ & $31(20.3 \%)$ \\
\hline
\end{tabular}

* Cumulative prevalence of type of offense adds up to more than $100 \%$ as cases can be categorized in more than one type of offense following their last interpelation.

Table 2: Prevalence of attested changes of behavior observed during the 2 years following the offense

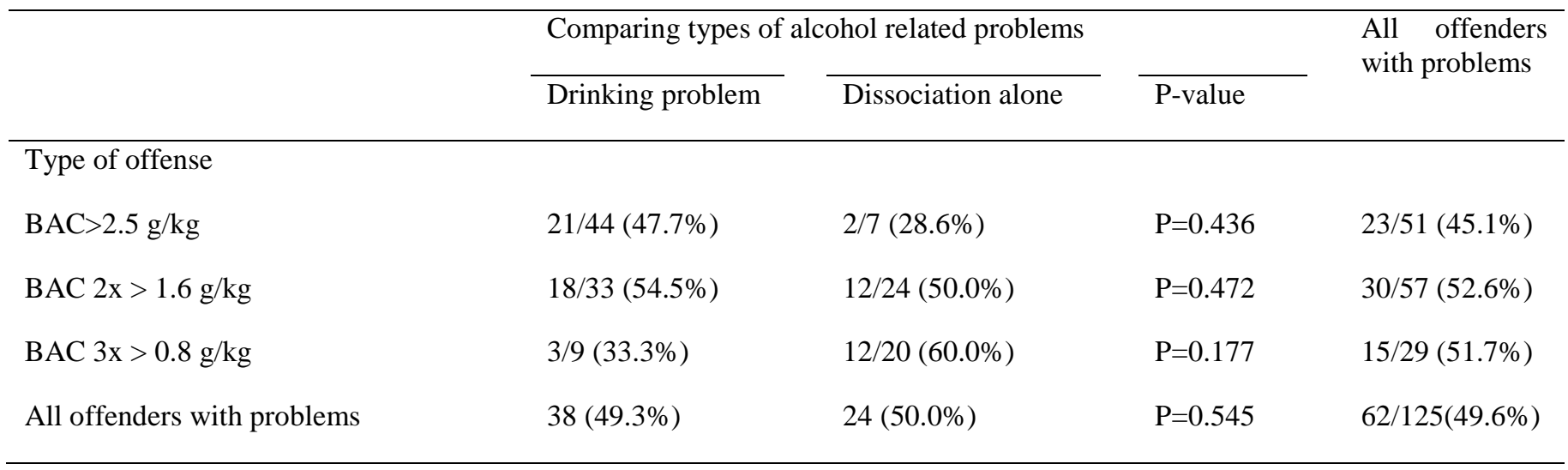




\section{Figure 1:}

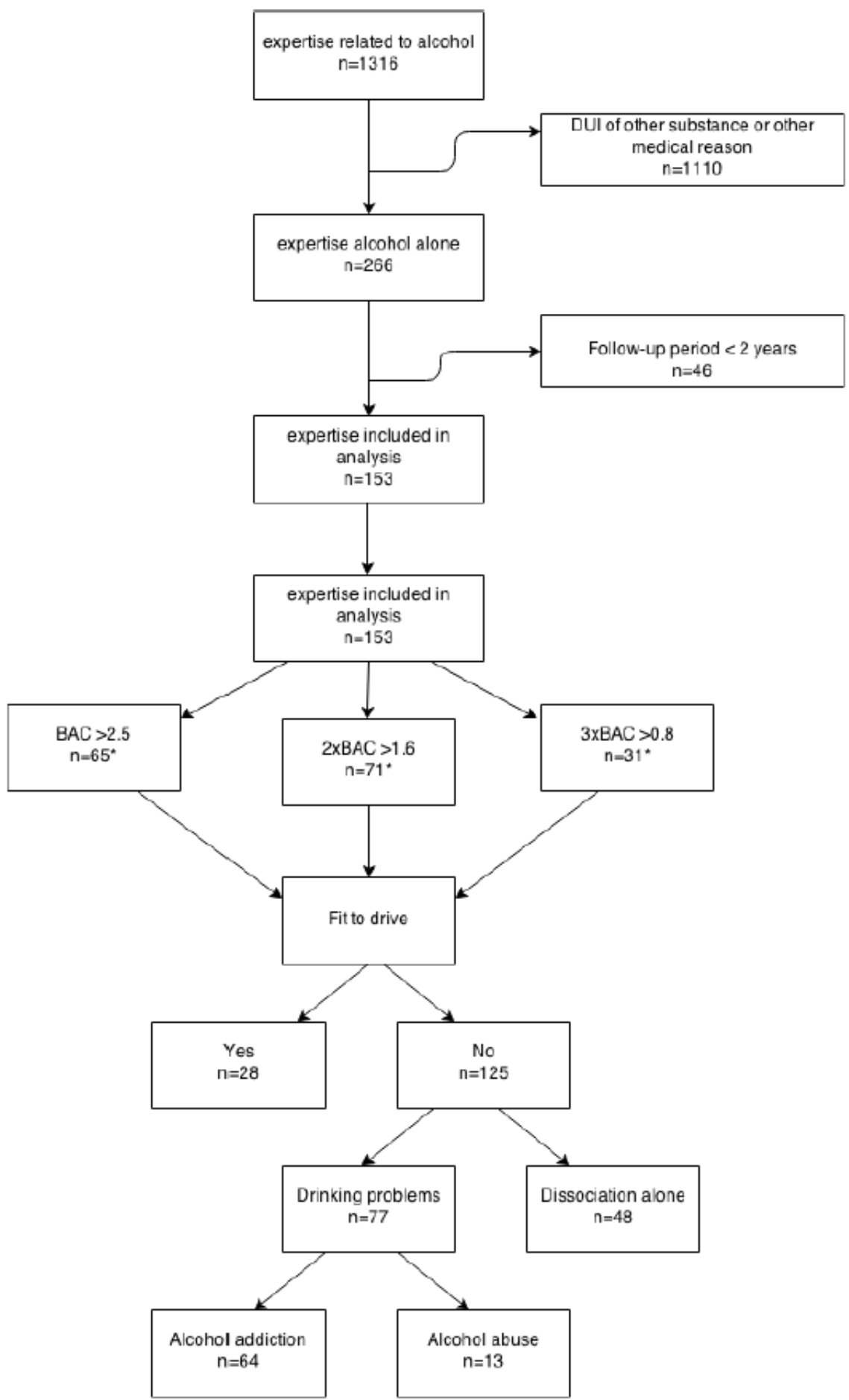

"= some adds up to more then the total number of offenders as participants can be in more than one category afier their last offense 